\title{
Save the children from screen overuse
}

\author{
Nayana Liyanarachchi \\ Department of Paediatrics, Faculty of Medicine, Univesity of Ruhuna, Galle, Sri Lanka.
}

Correspondence: Dr. N.D. Liyanarachchi

e-mail: liyanarachchiuk@yahoo.co.uk

https://orcid.org/0000-0003-3920-8653

Submitted on 05.02.2021 and accepted for publication on 20.05.2021

\section{Introduction}

There has been a marked increase in the use of screen-based devices over the last decade. Screenbased devices are electronic devices with a screen that is used to visualise digital images or videos. Traditional screen-based devices are televisions and computers while the newer versions are smartphones, tablets, and $i \mathrm{Pads}^{\mathrm{TM}}$. Now more than ever, children, irrespective of their age have unlimited access to a wide variety of screen-based devices. They spend lots of time engaged in screenbased activities, such as interacting on social media, playing video games, and surfing the Internet.

The screen-based media (SBM) have a strong influence on children, falling into their immediate social environment at present. Confinement of children into homes during the recent COVID-19 pandemic resulted in the escalation of screen use time. SBM has a positive impact on children today as it helps as a practical way to continue their education from home. However, there are growing concerns about the negative impact of SBM on children. Hence, parents should be aware of the harmful effects of screen overuse to prevent their children from screen overuse.

This review elaborates on the magnitude, impact, and responsibility of the parents and society regarding screen overuse among children.

\section{The magnitude of the problem}

Screen time is defined as the amount of time someone spends looking at an electronic device with a screen such as a television, computer, or smartphone (1). According to the recommendation of the American Academy of Paediatrics (AAP) and World Health Organization (WHO), the maximum screen use time allowed for children is two hours per day, and the time allowed for the screen varied with the age of the child (2). There is research evidence to show that children from all parts of the world are exceeding this limit. British adolescents spend 6.1 hours and American children spend 7.5 hours on screens per day (3). Screen overuse is a major issue among Sri Lankan children as well although we have done a limited research on this field. In a hospital-based survey done among 109 children at Lady Ridgeway Hospital for Children, Colombo, Sri Lanka on screen use time, it was found that more than $70 \%$ had exceeded two hours AAPlimit.

\section{Impact of screen overuse on children}

Children acquire early developmental and functional skills throughout childhood, with zero to five years being the predominant period where these skills are acquired (4).

To have optimal development, children need to grow up in an environment with adequate social, emotional, and educational inputs. Having a safe and loving home and spending time with family and friends, playing, singing, reading, and talking is very important to achieve maximum brain development. Screen overuse can have a negative impact since it results in reduced opportunities for social interaction, reduced chance for active learning and physical activity. The risks of exposure 
to violence, sexually explicit content and cultural stereotypes are also matters of concern (4).

Several studies have shown that excessive screen use is negatively related to the psychological and social development of children as this robs the time required for social activities of children (5).

American Psychological Association states a clear connection between aggression and video game violence $(6,7)$. A study conducted among 1200 students in Kandy, Sri Lanka reported a clear association between changes in behaviour following excessive screen time. Poor attention, violent behaviour, and hyperactivity were the observed behavioural changes (3). Depression and loneliness are also known to associate with internet addiction resulting in social isolation (8).

Furthermore, playing with peers is an important activity for the healthy development of the brain. It improves the problem-solving skills and creativity but also the social and emotional skills like empathy, managing emotions, building healthy relationships. Unfortunately, now children spend less time playing with real friends and spend more time on the screen, playing video games with virtual friends whom they may not have even seen before.

Excess screen use reduces the opportunities for parent-child interactions like shared reading and playing together with toys. Studies have shown that language development is delayed and academic achievements are decreased in children who have fewer parent-child interactions (9). Nowadays parents use screen-based devices, especially smartphones as a pacifier to console their children. Some parents themselves have generous attitudes towards smartphones and use them to entertain their children, especially during feeding.

Finally, children with higher levels of screen use, tend to be having a sedentary life which leads to a high risk of obesity (10). Poor food habits could also be a result of screen use as children tend to eat unhealthy food which is advertised on the television.

Events occurring in the early years of the life of the child are very important for his achievements during the later life. Excessive screen use among children is likely to continue throughout life and this may result in a great loss in their productive life.

\section{Responsibility of the parents and the society}

Parents should realise the negative effects of screen overuse on children and efforts should be taken to prevent children from getting addicted to the screen. They can impose some ground rules at home like banning screen devices such as televisions and smartphones in the dining table and bedroom. Parents can be good role models for children. It is the responsibility of the parents to minimise their own screen time and guide their children regarding their screen usage. Parents should not let the television, computer, or smartphone disrupt the parent-child interaction at home. Engaging in playing and quality time with family will aid in the development of essential skills like language, self-regulation, and creativity for children less than 5 years of age (11). Parents should make sure media does not take the place of adequate sleep, physical activity, and other behaviours essential to health.

Healthcare professionals and professional bodies providing social care to children should take a lead in taking this message to the public. The Australian and Canadian governments state that screen viewing time should be limited to less than one hour for children between two to five years (2). WHO also recommend that sedentary screen time for children between the ages of three to four years should not exceed one hour, and also states that lesser sedentary screen time is preferable (12). According to the WHO, screen time is not recommended for infants and toddlers below 18 months, except video chatting with parents or grandparents. Preschoolers ( 2 - 5 years) and primary schoolers (6-10 years) are allowed only for one hour and one and half hours respectively. As children grow up, parents can gradually give kids more control and choice in how they manage their time on the screen. For middle-school-age children (11 - 13 years) the recommended screen time is up to 2 hours per day.

In addition, a society-wide effort is essential to save children from screen overuse. Awareness programmes targeting preschool children and their parents on-screen overuse would be an investment in the future of the nation. 


\section{References}

1. Merriam-Webster. (n.d.). Screen time [Internet]. MerriamWebster.com. [cited 2021 Feb 2]. Available from: https://www.merriam-webster.com/dictionary/screen time

2. Screen time guidelines by age [Internet]. Eyepromise. com. [cited 2021 Feb 2]. Available from: https://www.eyepromise.com/wp-content/uploads/2019/ 05/Screentime-Recommendation-Chart-Final_ AAPWHO.pdf

3. Sinnarajah $\mathrm{K}$, Balachandran $\mathrm{K}$, Thuraisingham $\mathrm{T}$. Association of screen time with academic performance and behaviour among primary school children of Kandy district Sri Lanka. Open J Pediatric Child Health. 2019; 4(1): 047-052. DOI: 10.17352/ojpch.000020

4. Tom Lissauer, Graham Clayden, Alan Craft. Illustrated Textbook of Paediatrics: with Student Consult Online Access, $04^{\text {th }}$ Edition. UK: Mosby Ltd.; 2011.

5. Hosokawa R, Katsura T. Association between mobile technology use and child adjustment in early elementary school age. PLoS One. 2018;13(7):1-17.

6. Media CS. Zero to Eight: Children's Media Use in America 2013 [Internet]. A Common Sense Media Research Study. [cited 2021 Feb 2]. Available from: file://C:/Users/user/Downloads/zero-to-eight-2013.pdf

7. Huesmann RR, Moise-Titus J, Podolski CL, Eron LD. Longitudinal Relations between Children's Exposure to TV Violence and Their Aggressive and Violent Behaviour in Young Adulthood: 1977-1992. Dev Psychol. 2003; 39(2): 201-221.
8. Yao M, Zhong Z. Loneliness, social contacts and Internet addiction: A cross-lagged panel study. Computers in Human Behaviour. 2014; 30: 164-170.

9. Tomopoulos S, Valdez P, Dreyer B, Fierman A, Berkule S, Kuhn $\mathrm{M}$, et al. Is Exposure to Media Intended for preschool children associated with less parent-child shared reading aloud and teaching activities? Ambul Pediatr. 2007 Jan 31; 7: 18-24.

10. Cox R, Skouteris H, Rutherford L, Fuller-Tyszkiewicz M, Dell'Aquila D, Hardy LL. Television viewing, television content, food intake, physical activity and body mass index: a cross-sectional study of preschool children aged 2 - 6 years. Heal Promot J Aust. 2012; 23(1): 58-62.

11. Australian Government Department of Health. Guidelines for Healthy Growth and Development for Your Child. 2017; Available from: http://www.health.gov.au

12. Canadian Paediatric Society Ottawa Society Ottawa, Ontario DHTF. Screen time and young children: Promoting health and development in a digital world. Paediatr Child Health [Internet]. 2017 Oct 9; 22(8): 461-8. Available from: https://doi.org/10.1093/pch/pxx123 